\title{
Przemysław Polak*
}

\section{BLĘDY W ZASTOSOWANIACH BPMN W RÓŻNYCH ASPEKTACH ZARZĄDZANIA PROCESAMI BIZNESOWYMI}

\begin{abstract}
Streszczenie
Złożoność BPMN (Business Process Model and Notation) jest powodem trudności w poprawnym stosowaniu notacji. Celem artykułu jest identyfikacja najważniejszych problemów, jakie sprawia wykorzystanie BPMN w różnych aspektach zarządzania procesami. Autor dokonał przeglądu publikacji związanych z zarządzaniem procesowym, ale niezwiązanych bezpośrednio z analizą systemów informacyjnych, w których wykorzystano do ilustracji BPMN. Na tej podstawie zidentyfikowano najczęściej występujące błędy syntaktyczne w modelowaniu za pomocą BPMN i oceniono skalę tego zjawiska. Analiza wykazała, że największe trudności sprawia poprawne zastosowanie przepływów komunikatów oraz zdarzeń typu komunikat, a także rozróżnienie uczestników i wykonawców oraz ich poprawne reprezentowanie na diagramach w postaci basenów i torów.
\end{abstract}

Słowa kluczowe: zarządzanie procesami biznesowymi, modelowanie procesów biznesowych, BPMN

\section{Wprowadzenie}

Ostatnie lata przyniosły w dziedzinie modelowania procesów biznesowych ogromny wzrost popularności notacji BPMN (Business Process Model and Notation). Notacja ta posiada cechy różniące ją w sposób znaczący od popularnych dotychczas notacji modelowania procesów, takich jak np. EPC (Event-driven Process Chain). BPMN charakteryzuje się bardzo dużą złożonością semantyczną i syntaktyczną, wynikającą przede wszystkim z zastosowań informatycznych notacji wymagających odpowiedniego poziomu szczegółowości umożliwiającego precyzyjne opisanie procesów biznesowych w celu ich implementacji

\footnotetext{
* Przemysław Polak, dr, Szkoła Główna Handlowa w Warszawie, Instytut Informatyki i Gospodarki Cyfrowej, e-mail: ppolak@sgh.waw.pl
} 
w systemie informatycznym, szczególnie w przypadku modelowania procesów wykonywalnych. Jednak ta złożoność jest powodem trudności w poprawnym stosowaniu notacji.

BPMN na pierwszy rzut oka przypomina tradycyjny schemat blokowy, jednak nim nie jest. Mówi się wręcz o paradoksie tej notacji. Jej unikalne możliwości wynikają właśnie z tego, że różni się od tradycyjnych schematów blokowych (Silver, 2011, s. 3). Niestety informatycy, przyzwyczajeni do wykorzystywania schematów blokowych, często nie rozumieją istoty modelowania procesów biznesowych i w efekcie popełniają zasadnicze błędy w zastosowaniu BPMN.

BPMN został stworzony z myślą nie tylko o modelowaniu procesów biznesowych i ich prezentacji w postaci diagramów, ale przede wszystkim jako notacja do definiowania procesów wykonywalnych. Skutkiem tego jest jego złożoność semantyczna i syntaktyczna, która może sprawiać problemy twórcom modeli. Tendencja do ,informatyzacji” notacji nasiliła się po połączeniu się w 2005 roku konsorcjum BPMI.org (Business Process Management Initiative), które opracowało pierwsze wersje BPMN, z konsorcjum OMG (Object Management Group), odpowiedzialnym m.in. za rozwój standardu UML. Zwrócono też uwagę na fakt, że koncepcja BPMN ma wiele cech wspólnych z diagramami aktywności (List, Korherr, 2006, s. 1535). Tendencja ta szczególnie uwidoczniła się w najnowszej wersji BPMN 2.0, w której bardzo widoczny jest wpływ informatyczny na ten standard (Silver, 2011, s. 6-7). Widać to np. w silnym powiązaniu z potrzebami tworzenia systemów informatycznych zgodnie z wymogami architektury zorientowanej na usługi (SOA - Service-Oriented Architecture) (Scheithauer, Hardegen, 2011).

Nadmierna złożoność i szczegółowość notacji dla części zastosowań wymogła potrzebę wyróżnienia poziomów złożoności procesów (Silver, 2011, s. 15). W tym celu standard BPMN 2.0 definiuje trzy podklasy zgodności (OMG, 2011, s. 2):

- poglądową (descriptive),

- analityczną (analytic),

- wykonywalną (common executable).

Jednak standard określa tylko, które elementy języka muszą być wspierane dla poszczególnych podklas, nie zawiera natomiast zaleceń składniowych. Można je natomiast znaleźć w innych publikacjach (zob. np. Silver, 2011).

Wydaje się jednak, że wielu twórców modeli nie dostrzega różnic między tymi poziomami modelowania i w efekcie niepotrzebnie wykorzystuje niektó- 
re elementy notacji, nadmiernie komplikując tworzone diagramy, co utrudnia możliwość ich zrozumienia przez niedoświadczonych czytelników. Osoby wykorzystujące notację w różnych aspektach zarządzania procesami mają kłopoty w zrozumieniu i prawidłowym zastosowaniu niektórych elementów notacji, co prowadzi do tworzenia modeli niepoprawnych pod względem syntaktycznym, a w efekcie do niejednoznaczności modeli i błędnej ich interpretacji (Freund, Rucker, 2014, s. 8).

Problemy poprawnego modelowania procesów biznesowych występują także w przypadku stosowania innych mniej złożonych notacji. I w tych przypadkach najczęściej powtarzające się błędy są związane ze specyficznymi regułami składniowymi języka. Na przykład, w diagramach z użyciem EPC najczęstszym błędem okazało się umieszczenie dwóch funkcji bezpośrednio po sobie bez wymaganego przez reguły syntaktyczne rozdzielającego je zdarzenia (Szczęśniak, 2010, s. 114). W przypadku BPMN, który jest notacją znacznie bardziej złożoną niż EPC (Recker, Dreiling, 2007, s. 358), o wiele łatwiej jest popełnić błędy składniowe.

Złożoność BPMN w połączeniu z różnorodnością celów tworzenia modeli (czego objawem jest wyróżnienie podklas zgodności) powoduje różnice w stylu modelowania $\mathrm{w}$ tej notacji wynikające $\mathrm{z}$ różnicy doświadczeń twórców modeli. Wcześniejsze badania autora wykazały kontrasty w stylu modelowania wśród studentów studiów podyplomowych uczących się modelowania w BPMN w zależności od ich wykształcenia i uprzednich doświadczeń zawodowych. U osób z doświadczeniem informatycznym, programistów i projektantów systemów informatycznych obserwowana była tendencja do nadmiernego uszczegółowiania diagramów i wykorzystania wielu elementów notacji nieadekwatnie do celu, w jakim tworzono modele. W niektórych przypadkach pojawiała się skłonność do wykorzystania BPMN tak jakby to był schemat blokowy. Natomiast osoby bez doświadczeń informatycznych, najczęściej pracujące na stanowiskach specjalistów w różnych obszarach funkcjonalnych organizacji, unikały stosowania trudnych elementów notacji, a niekiedy miały problemy z poprawną interpretacją niektórych konstrukcji języka (Polak, 2014, s. 322-323).

Przedstawione powyżej obserwacje pozwalają postawić tezę, że diagramy w BPMN tworzone w ramach działań związanych z różnymi aspektami zarządzania procesami, ale nie z określeniem wymagań dla systemu informatycznego, mogą zawierać liczne błędy związane z użyciem niektórych złożonych struktur notacji. Celem przeprowadzonego przez autora badania była identyfikacja naj- 
częściej występujących błędów w modelowaniu za pomocą BPMN i próba oceny skali tego zjawiska.

\section{Metoda przeprowadzenia badania}

Dobrym przedmiotem badania mającego na celu identyfikację błędów mogłyby być modele wytworzone w rzeczywistych organizacjach w ramach różnych przedsięwzięć związanych z zarządzaniem procesami biznesowymi. Niestety ze względu na poufność zawartych w nich informacji, organizacje nie są skłonne do udostępnienia ich do niezależnych badań. Analiza kilku kompletów dokumentacji procesów biznesowych, do których autor ma możliwość dostępu, nie zapewniłaby wiarygodności jej wyników. Częściowo posiadane dokumenty przygotowane zostały przez tych samych analityków biznesowych, w tym przez samego autora. W tej sytuacji styl modelowania nawet pojedynczego wykonawcy modeli mógłby mieć wpływ na wyniki końcowe. Aczkolwiek przegląd literatury wykazał, że podjęto próby podobnej analizy, w tym wypadku dla diagramów EPC, na przykładzie dokumentów pochodzących z zaledwie dwóch organizacji (Szczęśniak, 2010, s. 114).

Jedyna znaleziona przez autora publikacja zawierająca badanie jakościowe modeli procesów tworzonych za pomocą BPMN objęła modele z 6 przedsiębiorstw (Leopold i in., 2015, s. 3). Autorzy tej publikacji skoncentrowali się jednak przede wszystkim na błędach w logice procesów i spójności całych modeli. Natomiast błędy składniowe szczegółowo dyskutowane w niniejszej publikacji zostały zebrane w jednej kategorii błędów syntaktycznych (Leopold i in., 2015, s. 3).

W celu uniknięcia tego rodzaju zagrożeń, przedmiotem analizy zostały różne dostępne publikacje i podręczniki dotyczące rozmaitych aspektów zarządzania procesami biznesowymi, z pominięciem opracowań dotyczących systemów informatycznych zarządzania, a w szczególności publikacji dotyczących samej notacji BPMN. Publikacje były wyszukiwane zarówno wśród prac naukowych i podręczników drukowanych, jak i w internetowych bazach zawierających publikacje naukowe. Poszukiwania objęły pozycje w języku polskim i angielskim. W procesie wyszukiwania publikacji wykorzystane zostały takie słowa kluczowe, jak: zarządzanie procesami, zarządzanie procesami biznesowymi, modelowanie procesów, process management, business process management, BPM, process modeling.

Wyszukane publikacje zostały przejrzane pod kątem zastosowania BPMN do ilustracji zagadnień związanych z zarządzaniem procesami. Do dalszej 
szczegółowej analizy wybrano pozycje zawierające diagramy wykonane z użyciem tej notacji.

Znalezione w publikacjach diagramy zostały sprawdzone pod kątem zgodności semantycznej i syntaktycznej ze standardem BPMN. Zważywszy na czas wydania poszczególnych publikacji, wzięto pod uwagę zarówno najnowszy standard BPMN 2.0, jak i starsze jego wersje, aktualne w czasie, kiedy były przygotowywane poszczególne publikacje. Znalezione w diagramach błędy zostały przejrzane pod kątem podobieństwa i na tej podstawie zakwalifikowane do jednej z kilku kategorii.

\section{Analiza ilościowa zidentyfikowanych błędów w zastosowaniu BPMN}

W trakcie wyszukiwania publikacji ilustrowanych diagramami BPMN przejrzanych zostało kilkaset pozycji. Przegląd literatury został przerwany po zidentyfikowaniu 20 publikacji zawierających takie diagramy. Okazało się, że wiele, nawet stosunkowo nowych artykułów, korzysta do przedstawienia procesów biznesowych z innych notacji, przede wszystkim EPC. Jednak najczęściej pojawiały się proste diagramy niezwiązane z żadną złożoną notacją, ewentualnie korzystające z niektórych elementów graficznych popularnych notacji, ale z ignorowaniem reguł składniowych. Tego rodzaju sposób modelowania można określić terminem notacji prymitywnych. Tak więc w tym wypadku nie znalazła potwierdzenia opinia, że BPMN stał się dominującą notacją.

W analizowanej grupie znalazło się 5 publikacji polskojęzycznych i 15 angielskojęzycznych, a wśród tych ostatnich - dwie afiliowane przez autorów z polskich uczelni i ośrodków naukowych. Łącznie, spośród 20 analizowanych publikacji zawierających diagramy w BPMN, w 17 znaleziono błędy w użyciu tej notacji. Tak więc tylko $15 \%$ z nich było wolnych od nieprawidłowości o charakterze syntaktycznym. Ponadto jedna publikacja zawierała błąd semantyczny - element nieistniejący w notacji BPMN umieszczony w przebiegu procesu.

Najczęściej powtarzające się, zidentyfikowane błędy zostały zakwalifikowane do jednej z czterech kategorii:

- przepływy komunikatów,

- zdarzenia,

- bramki,

- tory i baseny. 
Niektóre błędy zostały zakwalifikowane jednocześnie do kilku kategorii. $\mathrm{Na}$ przykład błędne zastosowanie komunikatu może się wiązać zarówno z błędnie użytym zdarzeniem typu komunikat, jak i przepływem komunikatu. Jednak każdy zidentyfikowany błąd był w miarę możliwości przypisywany do jednej kategorii, w której w opinii autora mieściła się pierwotna przyczyna błędu.

W tabeli 1 zestawiono listę publikacji wraz z oznaczonymi kategoriami, do których zaliczono zidentyfikowane błędy. Pominięto trzy publikacje (Kopp i in., 2011; Szyjewski, 2011; Waszkowski, 2014), w których nie zostały zauważone przez autora żadne usterki w diagramach BPMN.

Tabela 1

Kategorie błędów syntaktycznych w zastosowaniu BPMN w wybranych publikacjach

\begin{tabular}{|c|c|c|c|c|}
\hline \multirow[b]{2}{*}{ Publikacje } & \multicolumn{4}{|c|}{ Kategorie błędów } \\
\hline & $\begin{array}{c}\text { przepływy } \\
\text { komunikatów }\end{array}$ & zdarzenia & bramki & tory $\mathrm{i}$ baseny \\
\hline Addamssiri $\mathrm{i}$ in., 2014 & $\mathrm{x}$ & & & \\
\hline Ayad $i$ in., 2012 & & $\mathrm{x}$ & $\mathrm{x}$ & $\mathrm{x}$ \\
\hline Bitkowska, 2013 & & $\mathrm{x}$ & & \\
\hline Brambilla i in., 2012 & & $\mathrm{x}$ & $\mathrm{x}$ & \\
\hline Bujanowska, Biały, 2011 & & & $\mathrm{x}$ & \\
\hline $\begin{array}{l}\text { Chang, Ramachandran, } \\
2014\end{array}$ & & $\mathrm{x}$ & & \\
\hline Duda, Stadnicki, 2011 & & & $\mathrm{x}$ & \\
\hline Duske i in., 2014 & & $\mathrm{x}$ & $\mathrm{x}$ & \\
\hline Habli i in., 2014 & & & & $\mathrm{x}$ \\
\hline Herbert, Sharp, 2013 & $\mathrm{x}$ & & & \\
\hline Jurczyk-Bunkowska, 2013 & $\mathrm{x}$ & $\mathrm{x}$ & & $\mathrm{x}$ \\
\hline Ko i in., 2013 & & $\mathrm{x}$ & & \\
\hline Lohrmann, Reichert, 2013 & & & $\mathrm{x}$ & \\
\hline $\begin{array}{l}\text { Marcinkowski, Gawin, } \\
2014\end{array}$ & & $\mathrm{x}$ & & $\mathrm{x}$ \\
\hline Michalik i in., 2013 & $\mathrm{x}$ & $\mathrm{x}$ & & \\
\hline Owen, Raj, 2003 & $\mathrm{x}$ & & $\mathrm{x}$ & \\
\hline Shahinyan, Krastev, 2013 & $\mathrm{x}$ & & & $\mathrm{x}$ \\
\hline
\end{tabular}

Źródło: opracowanie własne. 


\section{Przykłady najczęstszych błędów w diagramach BPMN}

Najczęstszym błędem są proste pomyłki w zastosowaniu elementów notacji, które często nie mają większego wpływu na zrozumienie modelowanego procesu. Tego rodzaju błędy są też w większości najłatwiejsze do eliminacji dzięki użyciu narzędzi, które posiadają wbudowaną funkcję identyfikacji błędów składniowych. Przykładami tego rodzaju usterek są np.:

- nieuzasadnione użycie przepływu warunkowego bezpośrednio wychodzącego z bramki wykluczającej (zob. rys. 1),

- użycie adnotacji do opisu warunku po bramce wykluczającej (Bujanowska, Biały, 2011, s. 10),

- brak zdarzenia początkowego przy jednoczesnym użyciu w diagramie zdarzenia końcowego (Brambilla i in., 2012, s. 225; Chang i Ramachandran, 2014, s. 77),

- brak oznaczenia warunku lub przepływu domyślnego po bramce wykluczającej (Duske i in., 2014, s. 5 (zob. rys. 2); Duda i Stadnicki, 2011, s. 278).
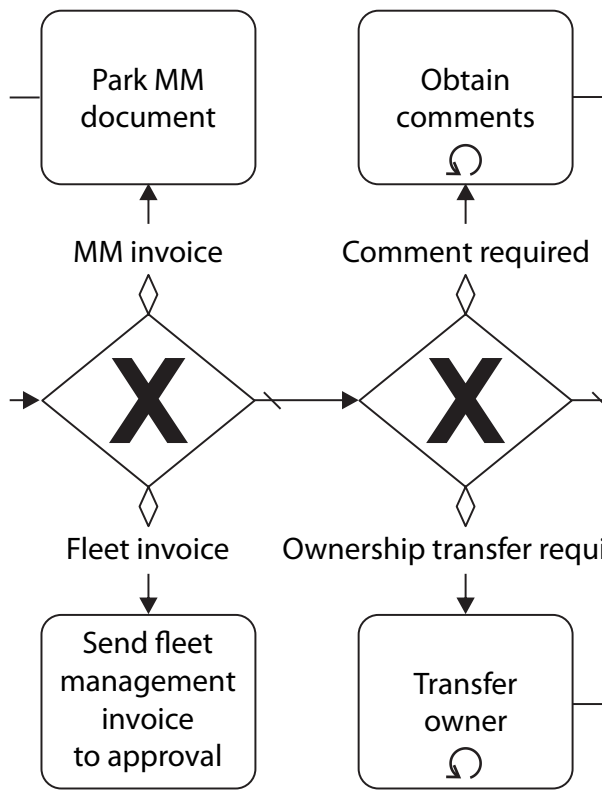

Comment required
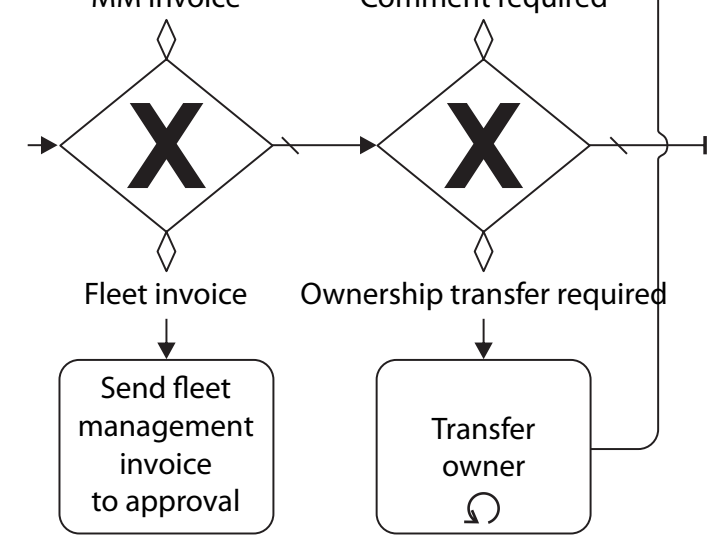

Rysunek 1. Nieprawidłowe użycie przepływów warunkowych po bramce wykluczającej Źródło: Lohrmann, Reichert (2013, s. 68). 


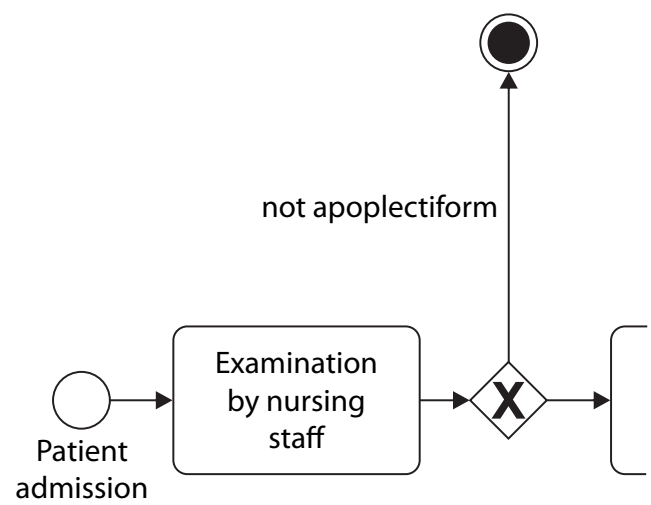

Rysunek 2. Przykład nieprawidłowego użycia zdarzenia zerwania (Terminate) i braku oznaczenia warunku lub przepływu domyślnego po bramce wykluczającej

Źródło: Duske i in. (2014, s. 5).

Jednak prosty błąd lub pominięcie elementu może uniemożliwić poprawne zrozumienie przebiegu procesu. Na przykład w jednym z modeli po bramce sterowanej zdarzeniami nie występują ani zdarzenia, ani zadania odebrania komunikatu (Ayad i in., 2012, s. 8, 10). W takiej sytuacji niemożliwa jest poprawna interpretacja przebiegu procesu.

W notacji BPMN występują trzy rodzaje skierowanych połączeń: przepływ sterowania (sekwencji), przepływ komunikatu i asocjacja ze strzałką. Może to prowadzić do błędnego użycia jednego $\mathrm{z}$ tych obiektów zamiast innego, na przykład zastąpienia przepływu sterowania przepływem komunikatu, co w efekcie prowadzi do braku przepływu sterowania wchodzącego do czynności lub wychodzącego z czynności (zob. np. Owen, Raj, 2003, s. 8, 16, 18; Michalik i in., 2013, s. 44). Komunikat może być też potraktowany jak przepływ sterowania, czego efektem są niepołączone fragmenty właściwego procesu (zob. np. Addamssiri i in., 2014, s. 73; Herbert, Sharp, 2013, s. 2234). Natomiast zastąpienie przepływu komunikatu przepływem sterowania prowadzi do umieszczenia jednego procesu w dwóch basenach, co oznaczałoby wykonywanie jednego procesu przez wielu uczestników (zob. np. Jurczyk-Bunkowska, 2013, s. 33).

Złożone reguły zastosowania zdarzeń w BPMN, wynikające $\mathrm{z}$ aż 13 rodzajów zdarzeń i 8 podstawowych wariantów ich występowania w diagramach, sprawiają szczególne trudności w ich użyciu zgodnie ze standardem. 


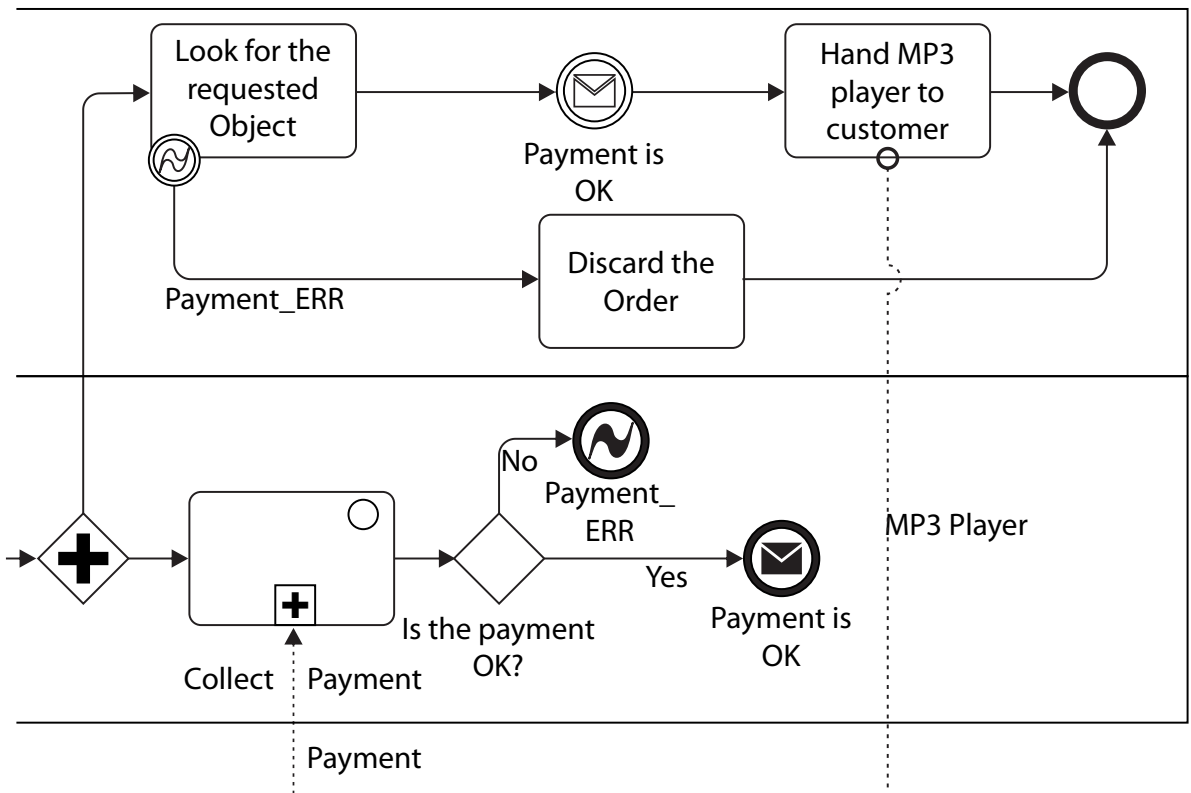

Rysunek 3. Błędne przekazanie komunikatu między zdarzeniami tego samego procesu Źródło: Chinosi, Trombetta (2012, s. 129).

Problemy budzi zastosowanie komunikatów. Zgodnie ze standardem komunikat powinien być skierowany do innego uczestnika, którego na diagramie reprezentuje basen (OMG, 2011, s. 120). Jednak wielu autorów modeli interpretuje dość swobodnie termin „komunikat”, najwyraźniej adresując go do innych wykonawców procesu. Problem jest znaczący, gdyż nawet publikacje dotyczące samego BPMN zawierają tego typu błędy. Na rysunku 3 przedstawiono fragment diagramu $z$ tego rodzaju błędem w artykule omawiającym sam standard. Komunikat wysyłany przez zdarzenie „Payment is OK” jest najwyraźniej odbierany przez inne zdarzenie odbierające komunikat $\mathrm{w}$ tym samym procesie, także opatrzone etykietą „Payment is OK”. Niekiedy komunikaty są literalnie rysowane między torami jednego basenu (Shahinyan, Krastev, 2013, s. 302, 304).

Podobny problem, jak zdarzenie typu komunikat, rodzi zdarzenie typu sygnał. Jest ono często identyfikowane z najbardziej powszechnym znaczeniem tego terminu - krótką wiadomością czy bodźcem. Tak rozumiany sygnał jest błędnie odróżniany od komunikatu wielkością i złożonością przesyłanej między uczestnikami wiadomości (zob. np. Jurczyk-Bunkowska, 2013, s. 33). 
Problemy z zastosowaniem komunikatów często są skutkiem nieprawidłowej identyfikacji uczestników i wykonawców, a w konsekwencji źle zdefiniowanych basenów i torów. Zdarzają się przypadki, gdy poszczególne działy organizacji umieszczane są w różnych basenach (zob. np.: Jurczyk-Bunkowska, 2013, s. 33; Habli i in., 2014, s. 118) albo niezależne organizacje reprezentowane są przez tory jednego basenu (zob. np. Marcinkowski i Gawin, 2014, s. 60).

\section{Podsumowanie}

Badanie wykazało, że stosowanie BPMN stanowi poważny problem dla twórców modeli. W zaledwie 15\% analizowanych publikacji nie dostrzeżono żadnych błędów. Co więcej, niektóre ze zidentyfikowanych błędów są bardzo poważne, co uniemożliwia pełne i poprawne zrozumienie modelowanego procesu.

Wyniki przeglądu publikacji przedstawione przez autora stoją w sprzeczności z wynikami badania modeli tworzonych w przedsiębiorstwach, według którego 99\% badanych modeli było wolnych od błędów syntaktycznych (Leopold i in., 2015, s. 3). Różnica ta może być spowodowana opracowywaniem tamtych modeli przez profesjonalnych analityków biznesowych z firm konsultingowych lub z branży IT. Natomiast modele badane w niniejszym opracowaniu były w większości autorstwa specjalistów od zarządzania. Dodatkowym czynnikiem mogła być nieznajomość notacji wśród recenzentów branżowych tych opracowań, przez co dopuszczono je do publikacji z tak rażącymi błędami.

Napotkane trudności i niewielka liczba znalezionych publikacji wykorzystujących BPMN wskazują, że specjaliści w dziedzinie zarządzania procesami niechętnie sięgają po tę notację. Wydaje się, że to właśnie złożoność i wynikająca z niej obawa przed błędami są przyczynami tego zjawiska. Popularniejsze jest wykorzystanie EPC, a zdecydowanie dominujące są modele prymitywne, nieoparte na żadnej standardowej notacji. Uzasadnione może być przeprowadzenie szerzej zakrojonych badań weryfikujących tę obserwację.

\section{Bibliografia}

Addamssiri N., Kriouile A., Balouki Y., Taoufiq G. (2014), Generating the PIM Behavioral Model from the CIM using QVT, ,Journal of Computer Science and Information Technology", vol. 2, no. 3-4, s. 55-81. 
Ayad S., Si-Said Cherfi S., Comyn-Wattiau I. (2012), Towards a semantic quality based approach for business process models improvement, Australasian Conference on Information Systems 2012, ACIS, Geelong, s. 1-11.

Bitkowska A. (2013), Zarządzanie procesowe we współczesnych organizacjach, Difin, Warszawa.

Brambilla M., Fraternali P., Vaca C., Butti S. (2012), Combining social web and BPM for improving enterprise performances: The BPM4People approach to social BPM, $\mathrm{w}$ : Proceedings of the 21st international conference companion on World Wide Web, ACM, s. 223-226.

Bujanowska A., Biały W. (2011), The identification and the modelling of processes of the use of the technical infrastructure in the hospital organization, „Systemy Zarządzania w Inżynierii Produkcji”, nr 4 (4), s. 7-12.

Chang V., Ramachandran M. (2014), A Proposed Case for the Cloud Software Engineering in Security, w: Emerging Software as a Service and Analytics. Proceedings of the International Workshop on Emerging Software as a Service and Analytics ESaaSA 2014, red. V. Chang, G Wills, R. Walters, Scitepress, s. 71-79.

Chinosi M., Trombetta A. (2012), BPMN: An introduction to the standard, „Computer Standards \& Interfaces", vol. 34, no. 1, s. 124-134.

Duda J., Stadnicki A. (2011), Modelowanie procesów rozwoju wyrobów, w: Komputerowo Zintegrowane Zarzadzanie. Tom 2, red. R. Knosala, Oficyna Wydawnicza Polskiego Towarzystwa Zarządzania Produkcją, Opole, s. 272-283.

Duske K., Müller R., Prüfer R., Stöhr D. (2014), A BPMN Model of the Charite Stroke Treatment Process, Institute für Informatik, Humboldt Universität zu Berlin.

Freund J., Rücker B. (2014), Real-life BPMN. Using BPMN 2.0 to Analyze, Improve, and Automate Processes in Your Company, Camunda.

Habli I., Al-Humam A., Kelly T., Fahel L. (2014), Integrating Safety Assessment into the Design of Healthcare Service-Oriented Architectures, w: 5th Workshop on Medical Cyber-Physical Systems. MCPS'2014, red. V. Turau, M. Kwiatkowska, R. Mangharam, C. Weyer, OASICS, Berlin, s. 113-123.

Herbert L.T., Sharp R. (2013), Workflow fault tree generation through model checking, w: Proceedings of the 2013 European Safety and Reliability Association ESREL Conference, Amsterdam, s. 2229-2236.

Jurczyk-Bunkowska M. (2013), Innovation Process Planning Model in the BPMN Standard, „Foundations of Management”, vol. 5, no. 2, s. 25-38.

Ko R.K.L., Lee S.S.G., Lee E.W. (2009), Business Process Management (BPM) Standards: a Survey, „Business Process Management Journal”, vol. 15, no. 5, s. 744-791.

Kopp O., Leymann F., Schumm D., Unger T. (2011), On BPMN Process Fragment Auto- 
Completion, w: Proceedings of the 3rd Central-European Workshop on Services and their Composition, ZEUS, s. 58-64.

Leopold H., Mendling J., Günther O. (2015), What we can learn from Quality Issues of BPMN Models from Industry, http://www.researchgate.net/publication/273258454 What_we_can_learn_from_Quality_Issues_of_BPMN_Models_from_Industry.

List B., Korherr B. (2006), An Evaluation of Conceptual Business Process Modelling Languages, w: Proceedings of the 2006 ACM symposium on Applied computing, ACM, New York, s. 1532-1539.

Lohrmann M., Reichert M. (2013), Understanding business process quality, w: Business Process Management. Theory and Applications, red. M. Glykas, Studies in Computational Intelligence, vol. 444, Springer, Berlin-Heidelberg, s. 41-73.

Marcinkowski B., Gawin B. (2014), BPMN a wymiar danych - ograniczenia i notacje komplementarne, ,e-mentor”, nr 2 (54), s. 57-67.

Michalik P., Štofa J., Zolotová I. (2013), The Use of BPMN for Modelling the MES Level in Information and Control Systems, ,Quality Innovation Prosperity”, nr 17 (1), s. 39-47.

OMG (2011), Business Process Model and Notation. Version 2.0, Object Management Group, http://www.omg.org/spec/BPMN/2.0 (3.01.2011).

Owen M., Raj J. (2003), BPMN and Business Process Management. Introduction to the New Business Process Modeling Standard, Popkin Software, New York.

Polak P. (2014), Wpływ notacji BPMN na podejście procesowe w zarzadzaniu, w: Nowe kierunki $w$ zarządzaniu przedsiębiorstwem - wiodace orientacje, red. J. Lichtarski, S. Nowosielski, G. Osbert-Pociecha, E. Tabaszewska-Zajbert, Prace Naukowe Uniwersytetu Ekonomicznego we Wrocławiu nr 340, Wrocław, s. 318-325.

Recker J.C., Dreiling A. (2007), Does it matter which process modelling language we teach or use? An experimental study on understanding process modelling languages without formal education, w: 18th Australasian Conference on Information Systems, red. M. Toleman, A. Cater-Steel, D. Roberts, Toowoomba, s. 356-366.

Silver B. (2011), BPMN Method and Style with BPMN Implementer's Guide, Cody-Cassidy Press, Aptos.

Scheithauer G., Hardegen B. (2011), Requirements Engineering for SOA Services with BPMN 2.0 - From Analysis to Specification, w: Business Process Model and Notation. Third International Workshop, BPMN 2011, Lucerne, Switzerland, November 21-22, 2011. Proceedings, red. R. Dijkman, J. Hofstetter, J. Koehler, Lecture Notes in Business Information Processing, vol. 95, Springer, BerlinHeidelberg, s. 160-165.

Shahinyan K., Krastev E. (2013), Evaluation metrics for Business Processes in an Academic Environment, w: Proceedings of the 7th International Conference on Information Systems and Grid Technologies, red. V. Dimitrov, V. Georgiev, Sofia, s. 297-306. 
Szczęśniak B. (2010), Syntax errors in the EPC diagrams of the integrated management system documents, „Scientific Journals Maritime University of Szczecin”, vol. 24 (96), s. 111-117.

Szyjewski G. (2011), Wykorzystanie modeli procesów biznesowych BPMN 2.0 do identyfikacji potrzeb zdalnego uwierzytelniania, „Metody Informatyki Stosowanej”, vol. 3 (28), s. 167-178.

Waszkowski R. (2014), Modele procedur $w$ działaniach organów nadzoru sanitarnego w przypadkach zatruć $i$ chorób zakaźnych przenoszonych droga pokarmowa, „Problemy Higieny i Epidemiologii”, nr 95 (1), s. 28-31.

\title{
FAULTS IN BPMN USAGE IN VARIOUS ASPECTS OF BUSINESS PROCESS MANAGEMENT
}

\begin{abstract}
Summary
The complexity of BPMN (Business Process Model and Notation) is the cause of difficulties in the correct use of the notation. This article aims to identify the most important problems of BPMN usage in various aspects of process management. The author conducted a review of articles illustrated with BPMN diagrams and related to process management, but not directly related to the analysis of information systems. On that basis, the most common syntactic errors in BPMN modeling were identified and the scale of that phenomenon was assessed. The analysis showed that the greatest difficulties were associated with the correct application of message flows, message events, as well as with the distinction of participants and actors, and their proper representation in the diagrams in the form of pools and lanes.
\end{abstract}

Translated by Przemystaw Polak

Keywords: Business Process Management, Business Process Modeling, BPMN 
